\title{
LinguísTiCa APLiCAda E InFormática: A INTERSEÇ̃̃o das duas Áreas na ConstruÇão de UM APLiCaTivo Para a FormaÇão de UM Banco de Dados de Suporte Didático no ENSINO DE ITALIANO

\author{
Carlos Antònio de Souza Perin ${ }^{*}$ \\ Lúcia Fulgèncio \\ Maryelle Joelma Cordeiro
}

RESUMO: Neste trabalho, propomos uma interseção entre a informática e a linguística aplicada ao ensino e à aprendizagem de italiano para construir um aplicativo online que permita a descrição linguística e a classificação de exercícios que podem ser utilizados no ensino e na aprendizagem da língua italiana. Inseridos no banco de dados e linguisticamente classificados, exercícios e textos didáticos podem ser recuperados pelo aplicativo na forma de listas de exercícios. O material didático inserido pode ser catalogado pelo professor em duas categorias: i) agrupamentos de exercícios definidos pelo professor por nível de ensino, por etapa de aprendizagem ou por categoria linguística; e ii) agrupamentos definidos pelo Quadro Comum Europeu de Referência (QCER), seguindo a classificação de habilidades linguísticas esperadas para estrangeiros, em cada nível de competência linguística. Ao permitir a seleção temática de exercícios para cada habilidade a ser desenvolvida, o aplicativo auxilia o professor na seleção e montagem de material didático adicional, evitando que, no desenvolvimento do curso de língua italiana, o professor fique preso somente ao livro didático. Além disso, o aplicativo auxilia na classificação e na sequência do material didático de acordo com os critérios do QCER.

\footnotetext{
* Universidade Federal de Minas Gerais, Belo Horizonte, MG (Brasil) carlos.perini@gmail.com / luciafulgencio@hotmail.com / maryellecordeiro@gmail.com
} 
PALAVRAS-CHAVE: ensino de língua italiana; aplicativo online; engenharia de software; QCER; digitalização de material didático de língua italiana.

ABSTRACT: In questo articolo proponiamo un 'intersezione tra due campi di studio, quello della linguistica applicata all'insegnamento e all'apprendimento di lingua italiana e quello dell'informatica, per costruire un'applicazione online che permette la descrizione e la classificazione linguistica degli esercizi che possono essere utilizzati per l'insegnamento e per l'apprendimento della lingua italiana. Inseriti nel database e linguisticamente classificati, esercizi e manuali possono essere poi recuperati dall'applicazione stessa sotto forma di liste di esercizi. I materiali didattici inseriti nell'applicazione possono essere catalogati dall'insegnante e suddivisi in almeno due categorie: i) raggruppamenti di esercizi stabiliti dall'insegnante, a seconda del livello di istruzione, della tappa di apprendimento o della categoria linguistica; e ii) raggruppamenti definiti in base ai parametri del Quadro Comune Europeo di Riferimento (QCER), secondo la classificazione delle competenze linguistiche previste per gli stranieri, ad ogni livello di competenza linguistica. L'applicazione permette la selezione tematica degli esercizi per ogni abilità da sviluppare, aiuta il docente nella selezione e nell'assemblaggio di materiale didattico aggiuntivo da offrire agli studenti, consentendo lo sviluppo dell'insegnamento del corso di lingua italiana in modo libero, non legato esclusivamente al libro didattico; inoltre, l'applicazione aiuta nella classificazione e nel sequenziamento di materiale secondo i criteri del QCER.

PAROLE CHIAVE: insegnamento della lingua italiana; applicazione online; ingegneria di software; QCER; digitalizzazione di materiale didattico di lingua italiana.

ABSTRACT: In this study we propose an intersection between two fields of study: applied linguistics in teaching/learning italian language and computer science, in order to build an online application that allows the linguistic description and classification of exercises to be used in Italian teaching/learning. The exercises and textbooks inserted into the database and linguistically classified can be retrieved by the application in exercise lists. The didactic material inserted can be catalogued 
by teachers in two categories: (i) in exercise groups defined by the teacher by level of education, by learning stage, or by linguistic category; and (ii) according to the Common European Framework of Reference (CEFR), following the classification of linguistic skills expected from foreigners, at each level of language competence. By allowing thematic selection of exercises for each skill to be developed, the application assists the teacher in the selection and elaboration of the additional didactic material, which prevents, in the didactic development of the Italian language courses, the teacher not to focus only on the textbook. In addition, the application assists in the classification and sequencing of the didactic material according to the CEFR criteria. KEYWORDS: Italian language teaching; online application; software engineering; CEFR; scanning didactic material of FL. 


\section{Introdução}

O interesse no desenvolvimento do aplicativo aqui descrito foi despertado, de modo específico, no desenvolvimento de um pequeno sistema para a formação de um banco de dados, a partir da digitalização do acervo fotográfico para o Museu Histórico Abílio Barreto (MHAB), da cidade de Belo Horizonte. Nesse aplicativo, usa-se um conjunto de palavras para descrever uma fotografia e, por meio dessas palavras, é possível filtrar e recuperar as fotografias utilizando o banco de dados do aplicativo. Vejamos um exemplo: o usuário do sistema, geralmente um estudioso de História, descreve uma fotografia como "Igreja São Francisco de Assis" e a registra assim no banco de dados utilizando a interface da Fig. 1 $^{1}$. Para posterior consulta no banco de dados das fotos, bastaria digitar no aplicativo a expressão "Igreja São Francisco de Assis" ou parte dela e as imagens catalogadas com essa expressão seriam recuperadas.

É essa a ideia que foi levada para o contexto da Linguística Aplicada e que descreveremos com mais detalhes a seguir.

1 Revista do Arquivo Público Mineiro, Ano XLIII, n 1, Janeiro - Junho de 2007, p. 160. Disponível em: http://www. siaapm.cultura.mg.gov.br/modules/rapm/search.php. Acesso: 05/05/2016. 
Figura 1. Sistema de Indexação do Museu Histórico Abílio Barreto (MHAB) - planilhas para identificação do acervo

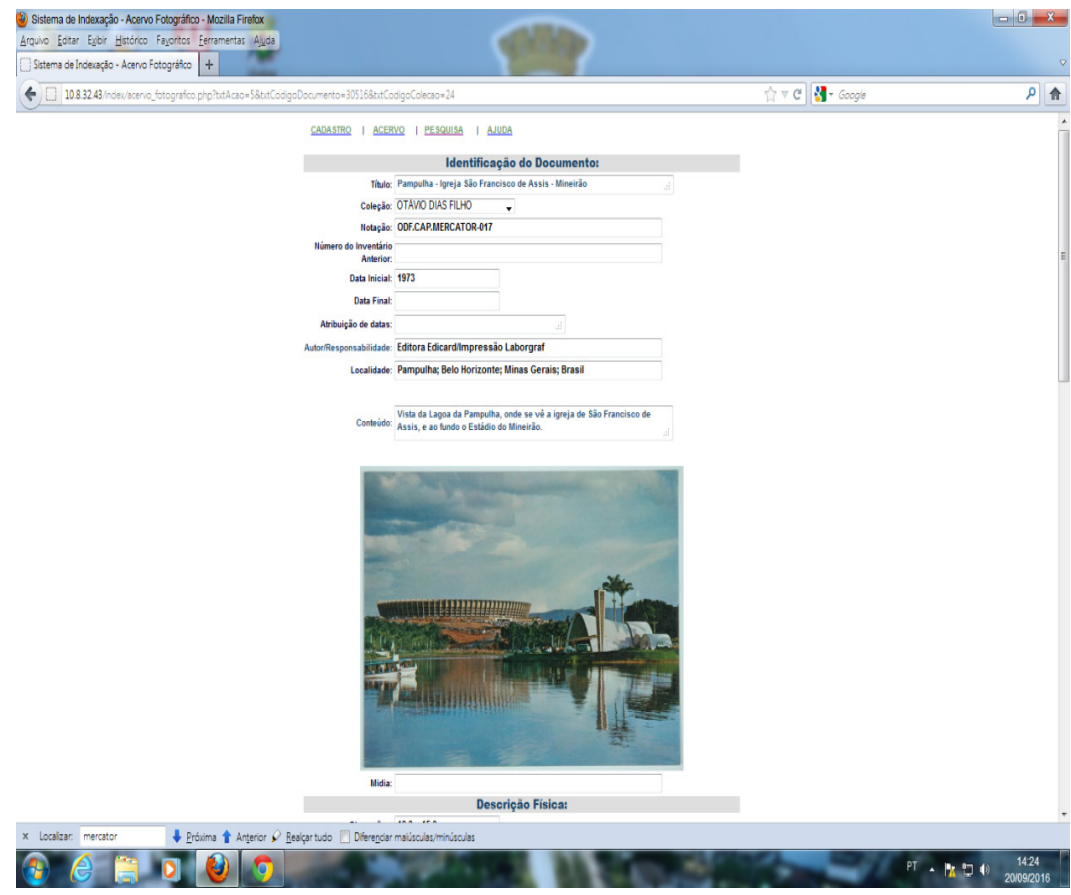

Partimos do pressuposto que, para adquirir uma nova língua, o aprendiz deva desenvolver as chamadas "quatro habilidades" - compreensão oral e escrita (ler e compreender) e produção oral e escrita (falar e escrever) - e que precise exercitar-se para avançar e construir sua interlíngua.

O professor - e aqui falaremos, em especial, do professor de língua italiana - pode ter dificuldade no planejamento e na seleção de exercícios específicos para cada uma das habilidades, para cada conteúdo gramatical e para cada nível linguístico como o fonológico, o morfológico, o sintático e o semântico. Além disso, poderá ter dificuldade em selecionar o léxico apropriado para o nível ou o contexto em que estará inserido o aluno².

A hipótese que sustenta o desenvolvimento de um software didático, como o que será aqui apresentado, baseia-se na concepção de que a organização do material didático pode levar, na atividade do professor, a uma maior precisão na atividade de encontrar os exercícios para 
atividades em sala e a uma melhoria de acesso ao material didático, facilitando e otimizando seu trabalho ${ }^{3}$. Do ponto de vista do aluno, o trabalho proposto poderá auxiliá-lo na autoaprendizagem e no desenvolvimento de sua proficiência linguística.

Esta pesquisa pode ser classificada de duas formas: a) como pesquisa exploratória, visando à descoberta de práticas que poderão modificar as existentes, por representar a introdução de procedimentos com o uso de tecnologias da informação; b) como pesquisa descritiva, por registrar e analisar sistemas técnicos de classificação de exercícios de ensino de língua italiana.

Quanto aos procedimentos, trata-se de uma pesquisa experimental, porque busca a descoberta de novas técnicas com o desenvolvimento de protótipos de software.

Por último, cabe acrescentar que a pesquisa se realiza em laboratório, uma vez que impõe a necessidade de controlar as variáveis que possam intervir no experimento.

\section{Fundamentação Teórica}

De acordo com Zambalde e Pádua (2006), a produção do aplicativo é classificada como uma pesquisa de natureza tecnológica, uma vez que objetiva a aplicação dos conhecimentos básicos da Linguística e de uma área da Ciência da Computação - a Engenharia de Software ${ }^{4}$ para o desenvolvimento de um novo produto: o "Aplicativo para suporte didático: catalogação de exercícios de ensino de língua italiana".

Para desenvolver um software didático aplicado ao contexto de ensino de língua italiana, é necessário realizar procedimentos descritivos no campo da Linguística e da Ciência da Computação. No campo linguístico é realizado nos níveis fonológico, morfológico, sintático e semântico, mas levando em conta também outros aspectos da língua. A partir desses níveis descritivos, o professor, baseado também nos conhecimentos sobre como funciona a mente humana quanto à aquisição da linguagem verbal e escrita, planejará a aula, considerando os aspectos que contribuirão para a aprendizagem do aluno. No campo da Ciência da computação a descrição é utilizada para a especificação de requisitos de um sistema computacional: quantos usuários utilizarão o sistema, se será online, se usará pouca ou muita memória e quais serão as funcionalidades do sistema como um todo.

A descrição linguística é importante também para verificar como falantes de diferentes línguas representam e referenciam seus conceitos no discurso do dia a dia, para verificar de que forma se realiza a aquisição da língua ${ }^{5}$, permitindo, por exemplo, dar suporte para a produção de exercícios utilizados no ensino de língua italiana.

3 Sobre o tema, ver Pichiassi (2007).

4 Cf. Filho (2003).

5 Cf. Santos (2002). 
No caso da computação, a descrição auxilia também para dar continuidade à manutenção de sistemas de softwares, pois se descreve um programa documentando-o. Isso significa descrever os módulos do programa e sua interdependência, suas estruturas de dados utilizadas, o formato de entrada e saída dos dados, explicação de como utilizá-los e sua complexidade que auxilia na mensuração de tempo de execução e ocupação de memória.

Por fim, utilizando o conceito de "objetos de aprendizagem" será feita a ponte para a descrição do aplicativo, que tem como funcionalidade principal a de permitir a descrição de exercícios, além de oferecer funcionalidades para sua busca e para montagem de listas, que não seriam possíveis sem a descrição. O suporte teórico linguístico para realizar a descrição dos exercícios linguísticos parte dos descritores do QECR.

\subsection{0 que é a Ciência da Computação?}

A Ciência da Computação é a ciência que estuda o computador, tendo como principal instrumento de estudo o próprio computador na hora de desenvolver programas. Um bom programador é, portanto, aquele que conhece as propriedades de cada componente do computador e sabe abstrair problemas do mundo real, levando-os para o mundo digital. Pensando na descrição dos componentes, podemos citar a capacidade de armazenamento e frequência de memória, a frequência do processador, a largura dos barramentos e suas formas de endereçamentos. No que diz respeito às decisões para o desenvolvimento dos programas, é preciso definir como saber identificar os problemas a serem resolvidos computacionalmente, e como resolvê-los incluindo, por exemplo, a escolha das linguagens de programação e dos paradigmas: se são estruturais, orientados a objetos, lógicos ou funcionais, entre outros fatores, como os do desempenho do programa e de como é a interação com o usuário.

\subsection{O que é a Linguística?}

A Linguística é a ciência que permite realizar a descrição do processamento das línguas naturais, ocupando-se dos estudos da linguagem humana, segmentados operacionalmente nas camadas descritivas (fonologia, morfologia, sintaxe, semântica, pragmática, discurso, entre outras). Essas camadas nos dão o entendimento de como os significados se realizam no cérebro humano e se codificam na prática da comunicação. Segundo Zuanelli (2009), a Linguística 
possui vários ramos de especificação como por exemplo: a Sociolinguística que estuda a relação entre linguagem e variáveis sociais; a Pragmática que trata o significado das expressões linguísticas como dependente do contexto e leva em consideração também os atos de fala e a entonação; a Linguística do texto e do discurso que analisam estruturalmente textos escritos. O texto torna-se assim o objeto de análise, considerado como unidade descritiva e significativa global. A Linguística possui também como área de estudo a chamada Linguística informática ou Linguística de Corpus, que estuda corpora linguísticos, analisando regras, tipologias e formatos com ferramentas eletrônicas; a Linguística contemporânea toca outras disciplinas: da Psicolinguística à Psicologia cognitiva, da Semiótica à Neurolinguística até as vastas áreas de intersecção com a ciência da computação, notadamente no campo da inteligência artificial e das pesquisas em ontologias linguísticas, os sistemas de representação do conhecimento com base em classificações linguísticas e relações semânticas entre palavras como a sinonímia, a antonímia, a hiperonímia, a hiponímia, a meronímia etc.

A Didática das línguas estrangeiras tem como objeto a Aquisição de línguas, seja em contextos estruturados como o escolar, seja em contexto não estruturado como o das comunidades humanas unilíngues e plurilíngues. Segundo Zuanelli (2009), seu objeto específico é a pesquisa sobre as fases e os problemas de aprendizagem relacionados com a dissimetria estrutural entre as línguas nos sujeitos bilíngues, bem como com os componentes psicológicos e metodológicos no ensino/ aprendizagem da língua.

\subsection{Os objetivos do QECR}

O já mencionado Quadro Europeu Comum de Referência para as Línguas (QECR, 2001) contém um conjunto de informações, que têm como referência o ensino das línguas. Esse conjunto é uma "completa síntese das linhas evolutivas desenvolvidas pelo Conselho Europeu nas políticas linguísticas dos anos 70". Os parâmetros de competência linguística estabelecidos pelo QECR são descritos para a língua italiana na chamada "Escala dos descritores de competência linguística", organizada por Mauro Pichiassi'.

A essa escala é dado o nome sillabo, definido como um guia que tem por objetivo especificar e ordenar em sequência os conteúdos de ensino em termos de "saber" e "saber fazer" na língua, ou mais simplesmente em termos de conhecimentos e/ou habilidades a serem adquiridos. De modo concreto, o sillabo é um plano detalhado que o professor traduz operativamente em ações e comportamentos dentro da sala de aula.

6 Professor na Università per Stranieri di Perugia. O sillabo do professor não foi publicado, mas tivemos acesso à escala proposta por meio de documentos da universidade. 
Os objetivos do QECR estão assim descritos no sillabo: (a) favorecer a difusão do plurilinguismo na Europa; (b) fornecer referências teóricas e oferecer instrumentos para quem trabalha no campo da educação linguística; (c) favorecer o reconhecimento e a equivalência de títulos de proficiência linguística.

A teoria contida na elaboração do QECR faz referência a uma aproximação orientada à ação, que interpreta o falante e o aprendiz de uma língua como verdadeiros atores sociais, os quais, por meio da ativação de estratégias oportunas, se dedicam a executar linguisticamente as atividades em determinados contextos e situações sociais.

O QECR desenvolve uma estrutura que integra uma dimensão de tipo vertical a uma dimensão de tipo horizontal. A dimensão vertical é dada por uma sequência gradual de níveis comuns de referência, formulados em termos de verdadeiros indicadores de capacidade linguística. Já a dimensão horizontal, é relativa a três principais categorias descritivas:

- as atividades linguísticas;

- as estratégias de aprendizagem;

- as competências linguístico-comunicativas.

Tal estrutura é modulada através das atividades de:

- produção oral e produção escrita;

- recepção oral e recepção escrita;

- interação oral e interação escrita;

- mediação.

Resumindo, para cada nível do sillabo, são descritos os seguintes aspectos:

a) tempo de duração do curso;

b) objetivo do curso;

c) exemplos de funções comunicativas necessárias para se adquirir a competência comunicativa desejada no nível em questão;

d) a competência sintática esperada para aquele nível de ensino;

e) a competência fonética e grafêmica;

f) a competência léxico-semântica;

g) os principais temas da comunicação, ou seja, as funções pragmáticas que devem ser desenvolvidas e exploradas naquele nível;

h) o grau e o nível de compreensão e produção de textos esperado;

i) a variedade de textos destinados à exercitação da leitura. 


\subsection{Os niveis do $Q E C R$}

O perfil da língua italiana insere-se na série de iniciativas promovidas pela divisão das políticas linguísticas do Conselho da Europa, voltadas para fornecer uma aplicação dos princípios e conteúdos do QECR. A obra de Parizzi e Spinelli, publicada em 2010, distribui em níveis de aprendizagem o sistema da língua italiana, tendo como base os projetos do Conselho Europeu de Educação Linguística. As listas de frequência do léxico apresentadas na obra têm como objetivo classificar e distribuir, em cada nível do QECR, o léxico da língua italiana que deve ser adquirido pelos aprendizes da língua. Essa listagem é usada para planejar o percurso didático de ensino e de aprendizagem do italiano, avaliar o nível de competência de um aluno e projetar o material didático a ser empregado em cada curso. As competências esperadas em cada um dos níveis do QECR são assim descritas:

\begin{tabular}{l|l}
\hline A1 & $\begin{array}{l}\text { Compreender, usar expressões familiares de uso cotidiano. Saber se apresentar e apresentar } \\
\text { os outros, fazer perguntas, pedir informações pessoais, responder às perguntas. Interagir de } \\
\text { modo simples. }\end{array}$ \\
\hline A2 & $\begin{array}{l}\text { Compreender frases isoladas e expressões de uso frequente, oferecer informações sobre a } \\
\text { família, bens, geografia local e o trabalho. Comunicar em atividades simples e de rotina. } \\
\text { Descrever em termos simples aspectos da própria vida e do próprio ambiente. }\end{array}$ \\
\hline B1 & $\begin{array}{l}\text { Compreender mensagens claras sobre assuntos familiares relacionados ao trabalho, à } \\
\text { escola e ao tempo livre. Lidar com situações em que é necessário se apresentar. Produzir } \\
\text { textos simples sobre assuntos familiares ou de seu interesse. Descrever experiências e } \\
\text { acontecimentos. Expor brevemente as razões de fatos e dar explicações sobre opiniões e } \\
\text { projetos. }\end{array}$ \\
\hline B2 & $\begin{array}{l}\text { Compreender as ideias fundamentais de textos complexos, que incluem assuntos de caráter } \\
\text { concreto e abstrato, contendo discussões técnicas do próprio setor de especialização. } \\
\text { Interagir com agilidade e espontaneidade, tanto que a interação com um falante nativo se } \\
\text { desenvolve sem excessiva fadiga ou tensão. Produzir textos claros e articulados sobre uma } \\
\text { ampla gama de assuntos e expressar sua opinião sobre um assunto da atualidade, expondo os } \\
\text { prós e contras das diversas opiniões. }\end{array}$ \\
\hline C1 & $\begin{array}{l}\text { Compreender uma ampla gama de textos complexos e mais longos e saber extrair o } \\
\text { significado implícito. Expressar-se de modo fluente e espontâneo, sem esforço excessivo } \\
\text { para encontrar as palavras. Usar a língua em modo flexível e eficaz para objetivos sociais, } \\
\text { acadêmicos e profissionais. Saber produzir textos claros, bem estruturados e articulados com } \\
\text { assuntos complexos, mostrando saber verificar as estruturas discursivas, os conectivos e os } \\
\text { mecanismos de coesão. }\end{array}$ \\
\hline
\end{tabular}



tratadas de diversas fontes, orais e escritas, reestruturando em um texto coerente os argumentos e as partes informativas. Saber expressar-se espontaneamente, de forma muito fluente e precisa, identificando as entrelinhas de significado, mesmo em situações mais complexas.

\section{O que veio primeiro? $O$ aplicativo ou a organização do conteúdo?}

Para conceber o aplicativo, foram usados os critérios de organização de conteúdo (do QECR e da comunicação digital, que sugere o uso de cores e contrastes binários como também o corpo e o tipo de caractere) e o modo de organização pessoal do autor. A organização manifesta-se no ato de planejar a lista, de selecionar ou propor exercícios segundo o critério do nível da turma ou do tema gramatical. Para a realização concreta do conteúdo a ser montado para uma aula (a lista de exercícios ou o conteúdo a ser projetado em sala), o ato de organizar é feito com o apoio do aplicativo, conceituado e definido para esse fim.

Utilizando o aplicativo, o professor pode executar procedimentos semelhantes aos do ato de elaborar uma organização manual, porém de modo muito mais rápido. Por exemplo, em vez de consultar uma grande série de livros, selecionando item por item, de forma manual, o professor pode consultar a lista já selecionada e armazenada no aplicativo. Certamente suas ações serão otimizadas, uma vez que é muito mais prático recuperar um conteúdo que se procurava e que está todo digitalizado e armazenado dentro do computador, e é ainda mais eficiente quando existe a funcionalidade para a seleção adequada (seguindo o QECR), como no software que propomos.

Para que fosse possível construir o aplicativo acima descrito, foram seguidos, de modo simplificado, os passos listados a seguir:

1. foram traduzidos os critérios de ensino/aprendizagem para a aquisição da língua do sillabo;

2. foram digitalizados vários livros didáticos e mapeados os índices temáticos nos grupos canônicos do QECR listados no sillabo;

3. foi desenvolvido um aplicativo que permite cadastrar, catalogar cada exercício e montar a lista de exercícios seguindo os critérios do QECR, bem como os critérios estabelecidos por professor;

4. foram inseridos no aplicativo os exercícios dos livros digitalizados, seguindo os critérios de descrição do QECR presentes no sillabo. 
Critérios particulares também podem ser inseridos, mas obedecendo a um guia, de forma a evitar classificações do tipo "outros", em que caberia qualquer assunto, e que, portanto, não contribuiriam para a categorização e futura seleção dos exercícios.

\section{Procedimentos metodológicos}

A seguir, serão ilustrados os procedimentos metodológicos adotados para a realização do aplicativo que estamos descrevendo.

\subsection{Seleção e digitalização do material didático}

Quanto ao material didático selecionado, foram utilizados aqueles dos primeiros níveis adotados pelo curso de italiano do Centro de Extensão da Faculdade de Letras da UFMG (CENEX - FALE - UFMG), cujas capas foram reproduzidas abaixo:

Figura 2. Capas dos manuais Linea Diretta vol.1 (2005), Italiano In vol.1 (2010), Nuovo Progetto Italiano, vol.1 (2013) e Espresso, vol. 1 (2003).
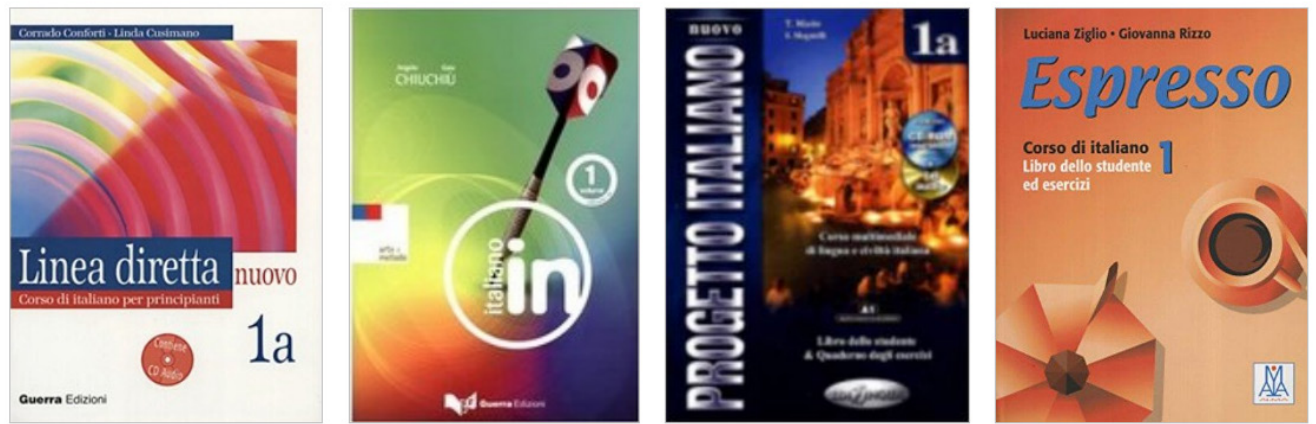

Os livros digitalizados foram tratados de modo que os exercícios pudessem ser extraídos da página do livro por meio de um programa de editor de imagens chamado Gnu Image Processing (GIMP) e, depois disso, salvos numa pasta do computador. Em seguida, os exercícios foram inseridos no aplicativo, onde foram classificados de acordo com a tabela do QECR, além de outras informações como a classificação original na fonte (o passo a passo para inserção de um exercício, sua classificação, recuperação e montagem de lista será mostrado na próxima seção). 
Para a classificação dos exercícios, foram realizadas as seguintes ações:

a. listar as classes de exercícios do material didático;

b. utilizar os sumários dos livros didáticos selecionados (além dos índices, são propostos critérios para a classificação do exercício, como gramática, léxico e funções comunicativas das convenções sociais);

c. alinhar essas classes com aquelas do QECR;

d. permitir que as buscas feitas na interface do aplicativo possam ser feitas por partes (seguindo o contexto do QECR ou o tipo de exercício: se de recepção ou de produção).

\subsection{Diagrama de casos de uso}

O diagrama de casos de uso é uma forma de ilustrar os atores e as funcionalidades do aplicativo e é também um modo de abstrair as principais funcionalidades do software para se ter uma visão geral do que se pode esperar dele. Os atores são representados com a figura "boneco de palitos" e os casos de uso com elipses. O ator de nosso programa é o professor, pois é ele quem realiza cada funcionalidade implementada no aplicativo. Cada caso de uso abstrai uma funcionalidade, ou seja, possui como título a ação que pode ser executada pelo ator e, por isso, esse título sempre será iniciado com um verbo no infinitivo.

Figura 3. Diagrama de casos de uso do aplicativo.

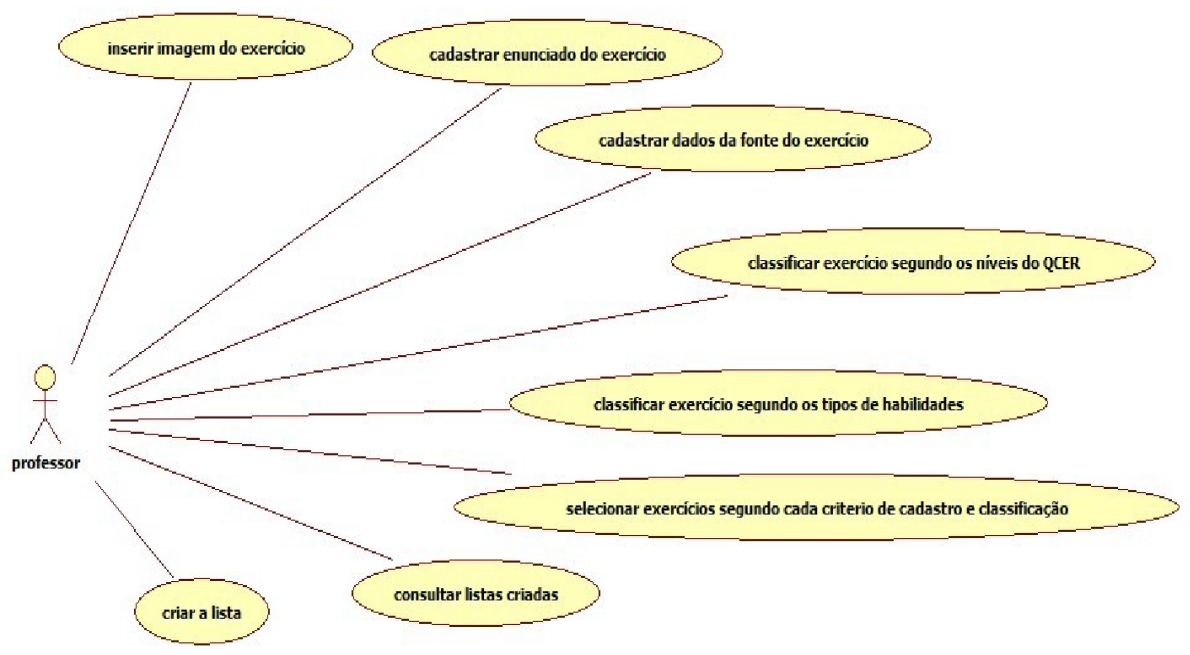




\subsection{Manual do usuário}

Com o computador ligado na Internet, é preciso abrir um navegador WEB (recomenda-se Firefox ou Google Chrome) e acessar o endereço www.ilmago.com.br. Aparecerá a tela exibida na Fig. 3 a seguir:

Figura 4. Tela de login de acesso

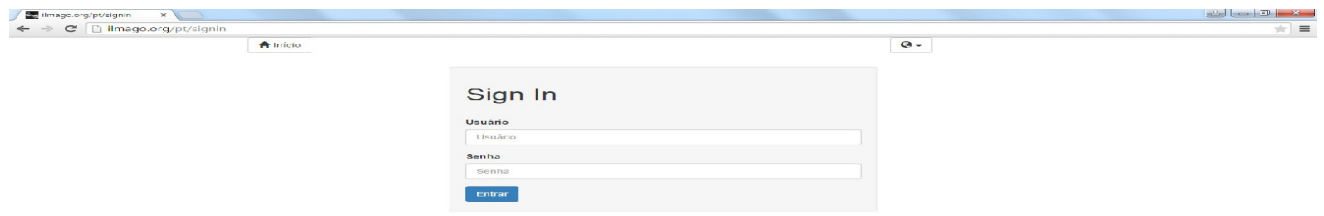

$\Leftrightarrow \theta+\theta \| m=$

Ao inserir as credenciais, aparecerá, como se vê na Fig. 5, a tela com as principais funcionalidades do aplicativo.

Figura 5. Tela com as principais funcionalidades

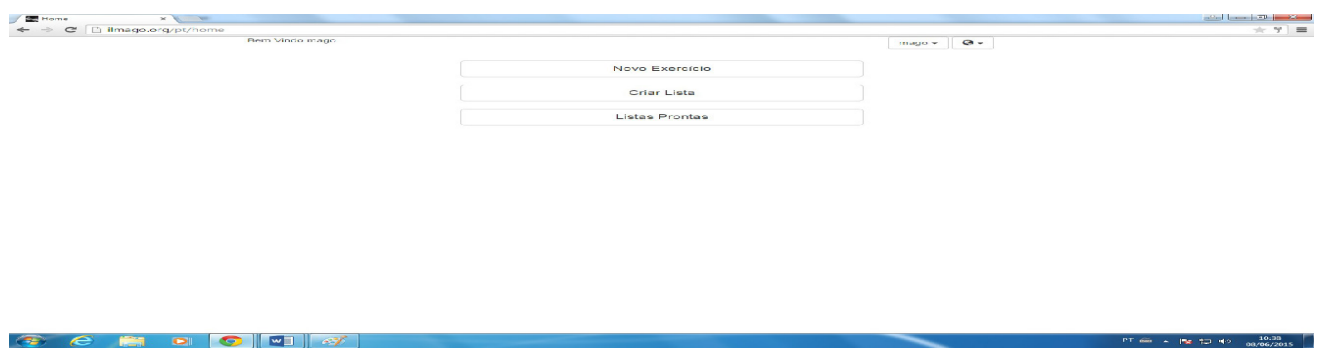

Para inserir um novo exercício, clicar na primeira funcionalidade, no botão "Novo Exercício", como ilustrado na Fig. 6 a seguir 
Figura 6 - Inserindo um novo exercício

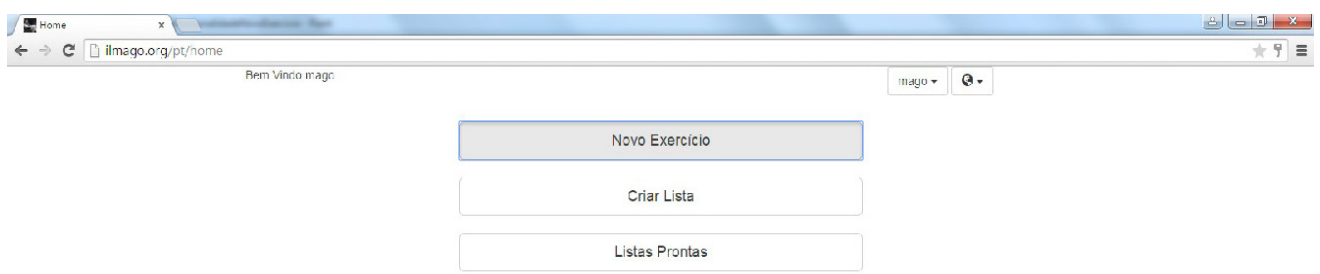

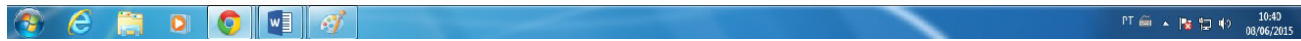

Após clicar no botão "Novo Exercício", aparecerá a tela para que se possa realizar o upload da imagem do exercício e sua classificação dividida em 5 abas "Anexo", "Enunciado", "Livro", "QECR" e "Tipo".

Figura 7 - Tela de upload da imagem e classificação do exercício.

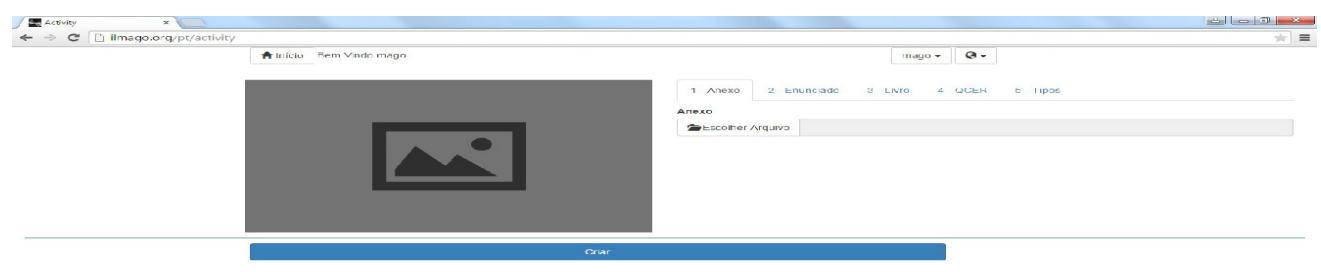


Ao clicar no espaço para inserir a imagem, aparecerá a pasta para selecionar o exercício previamente recortado.

Figura 8 - Tela de seleção da imagem do exercício para upload.

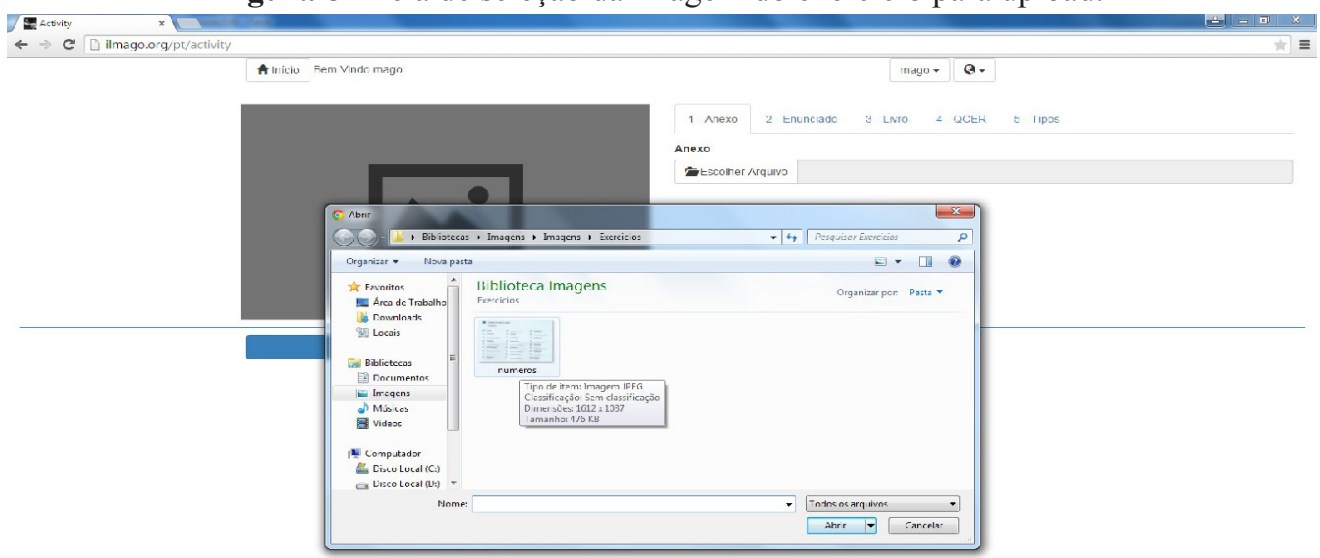

Se o arquivo for maior do que $3 \mathrm{MB}$, não será possível inseri-lo para não sobrecarregar o aplicativo. Nesse caso, aparecerá uma mensagem como na figura a seguir:

Figura 9 - Tela de upload de exercício com mensagem de erro.

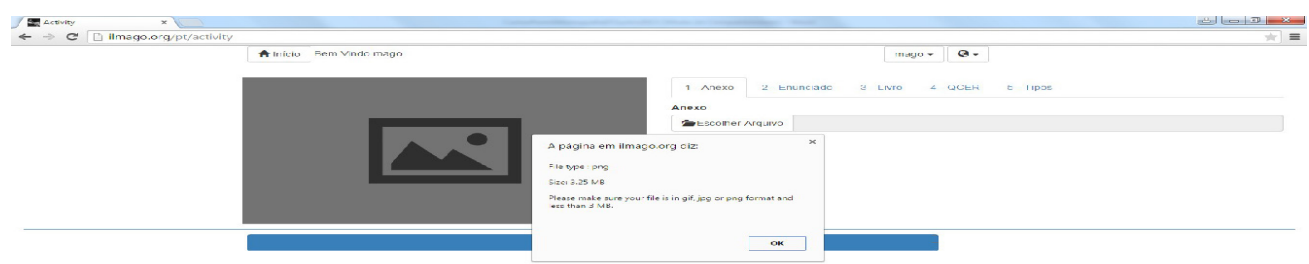


Caso o arquivo tenha até $3 \mathrm{MB}$ de tamanho, o arquivo será inserido no aplicativo como ilustrado na Fig. 10:

Figura 10 - Tela de upload do exercício com sucesso.

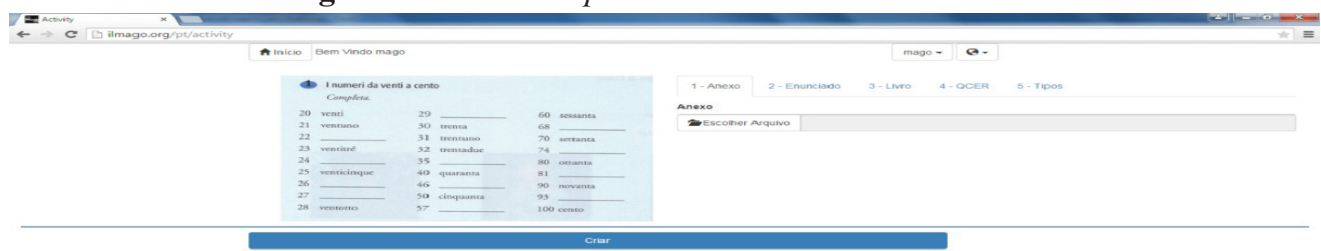

Feito o upload da imagem do exercício, começa-se a classificação, em cinco níveis, do exercício inserido. No primeiro nível, há a inserção de um anexo, caso o exercício seja acompanhado de um arquivo áudio (não foi aqui exemplificado porque é semelhante ao processo de upload da imagem do exercício); no segundo, insere-se o enunciado do exercício; no terceiro, os dados da fonte (livro didático); no quarto, informações sobre o nível de acordo com QECR, incluindo as competências de cada nível; e por último, no quinto, os tipos de habilidades (produção e/ou compreensão oral e/ou escrita). As próximas telas equivalem a cada um desses níveis de tratamento da informação do exercício.

Com a imagem do exercício inserida, o usuário precisa ir à aba "Enunciado" e inserir no campo com o mesmo nome o comando do exercício. 
Figura 11 - Inserindo o enunciado do exercício

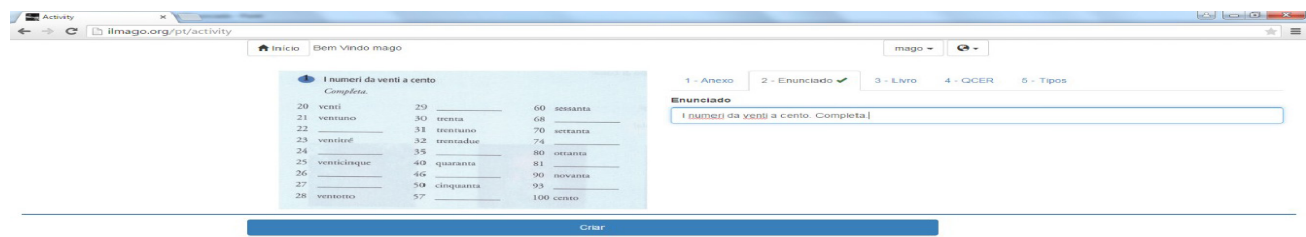

एक $P$ का $P$ क

Após mudar para a terceira aba, o livro é catalogado, conforme ilustrado na Fig. 12 a seguir.

Figura 12 - Inserindo o livro didático e a página onde se encontra o exercício

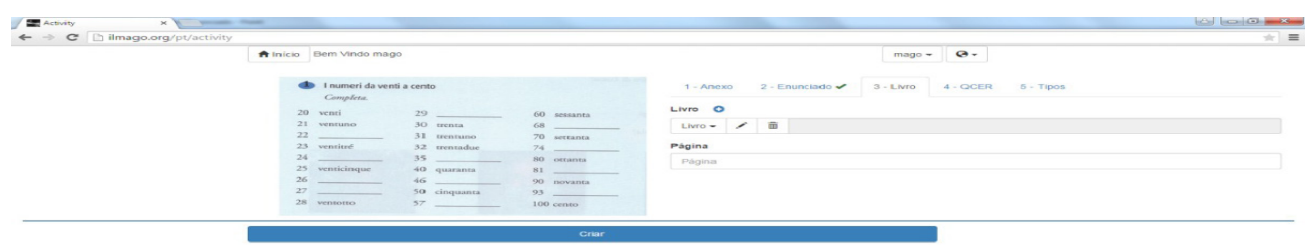

Caso o livro não tenha sido cadastrado no aplicativo, ele poderá ser cadastrado. Para tanto, deverá ser informado título, autor, número ISBN, ano da publicação, editora e uma imagem da capa do livro. Esses campos estão exibidos na Fig. 13 a seguir. 
Figura 13 - Inserindo os dados do livro didático

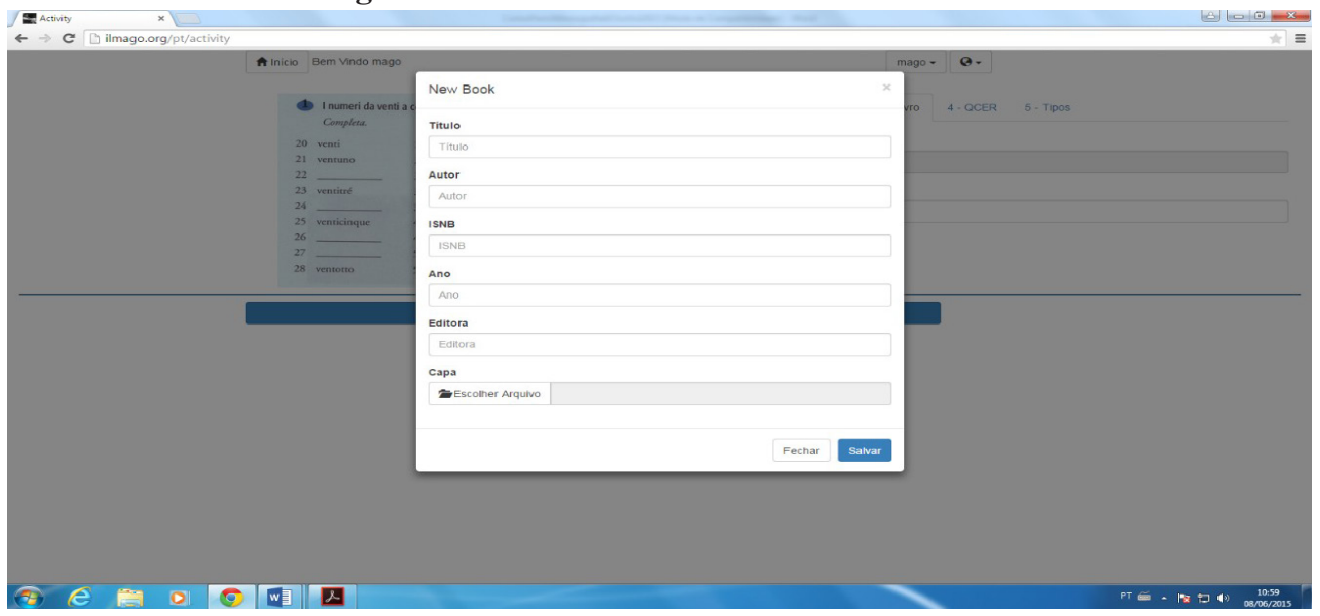

Cadastrada essa parte, é preciso ir para a aba 4, catalogar o exercício de acordo com o nível do QECR a que pertence o livro e acrescentar as competências (é o que no aplicativo é chamado “contexto"). Essas competências são os objetivos no QECR descritos na seção 2.3 e podemos dar foco às seguintes competências: a) a competência sintática esperada para aquele nível de ensino; b) as competências fonética e a grafêmica; c) a competência léxico-semântica e d) a competência das funções pragmáticas que devem ser desenvolvidas e exploradas naquele nível.

Figura 14 - Catalogação do nível do QECR e das competências linguísticas

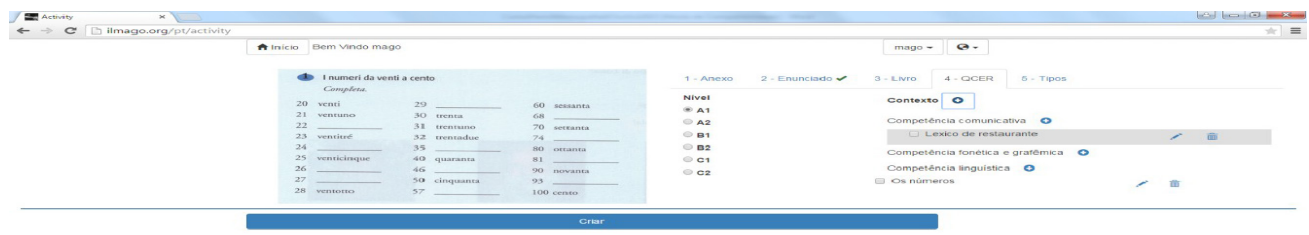


Por último, é necessário inserir os dados sobre as habilidades de compreensão e produção oral e escrita, como ilustrado na Fig. 15.

Encerrando a catalogação, basta clicar no botão "criar" para salvar o exercício no banco de dados do aplicativo e os dados usados na catalogação.

Figura 15 - Catalogação das habilidades de compreensão e produção orais e escritas
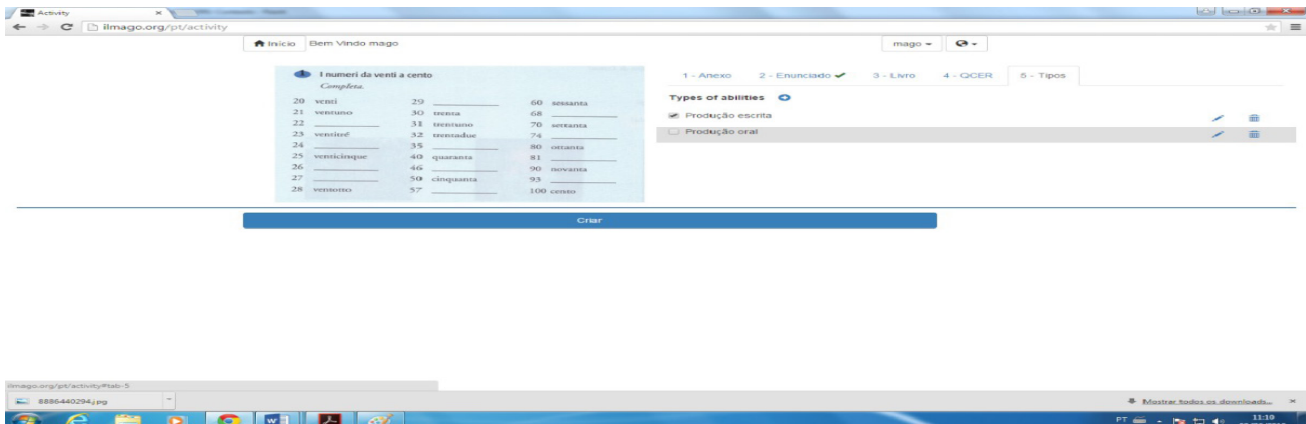

O próximo passo é a criação da lista de exercícios. Para isso, o usuário deve clicar em "home" no canto superior esquerdo e depois no botão da funcionalidade "Criar Lista", como ilustrado na Fig. 16 a seguir:

Figura 16 - Tela de funcionalidades: selecionando a criação de listas

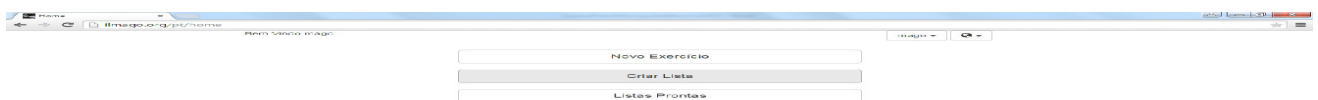

Selecionando essa funcionalidade, aparecerá uma tela com três cenários, como ilustrado na Fig. 17. O primeiro cenário, mais à direita, possui os critérios utilizados na classificação do exercício; nessa área, eles aparecem como modo de seleção; o segundo cenário apresenta o 
resultado de acordo com a seleção feita na coluna mais à direita; o terceiro é a prévia da lista, e é nele que aparecem os exercícios selecionados no segundo cenário.

Figura 17 - Ambiente de criação da lista de exercícios

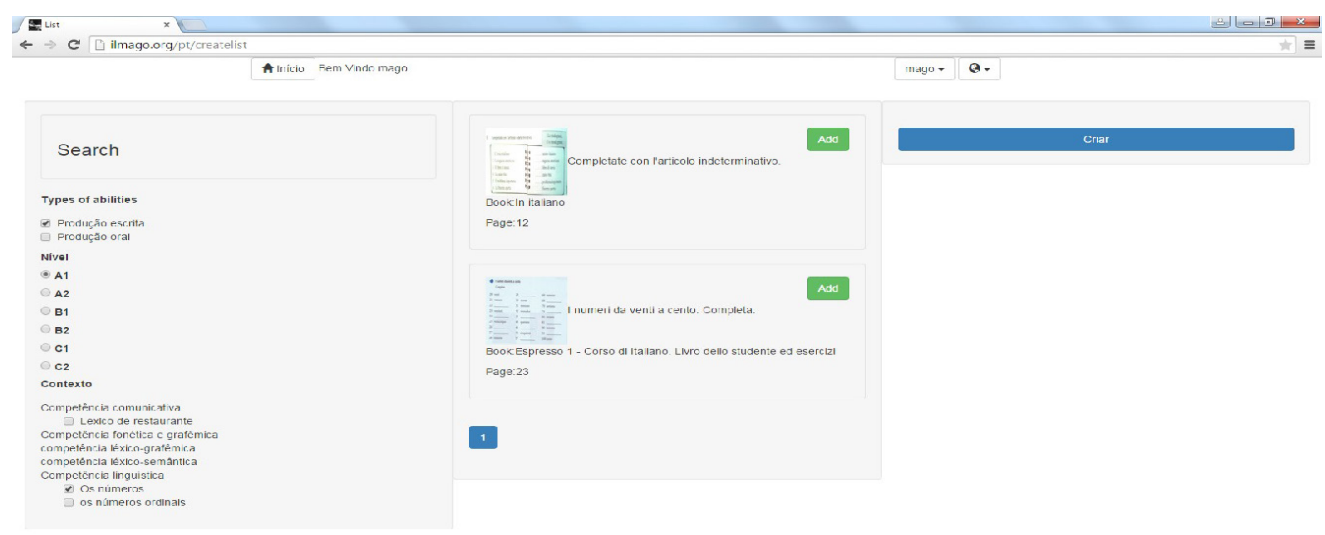

Ao clicar no botão "ADD” de um exercício, o software irá para a área 3, de previsão da lista como ilustrado na Fig. 18:

Figura 18 - Exemplo de exercício adicionado à lista de exercícios

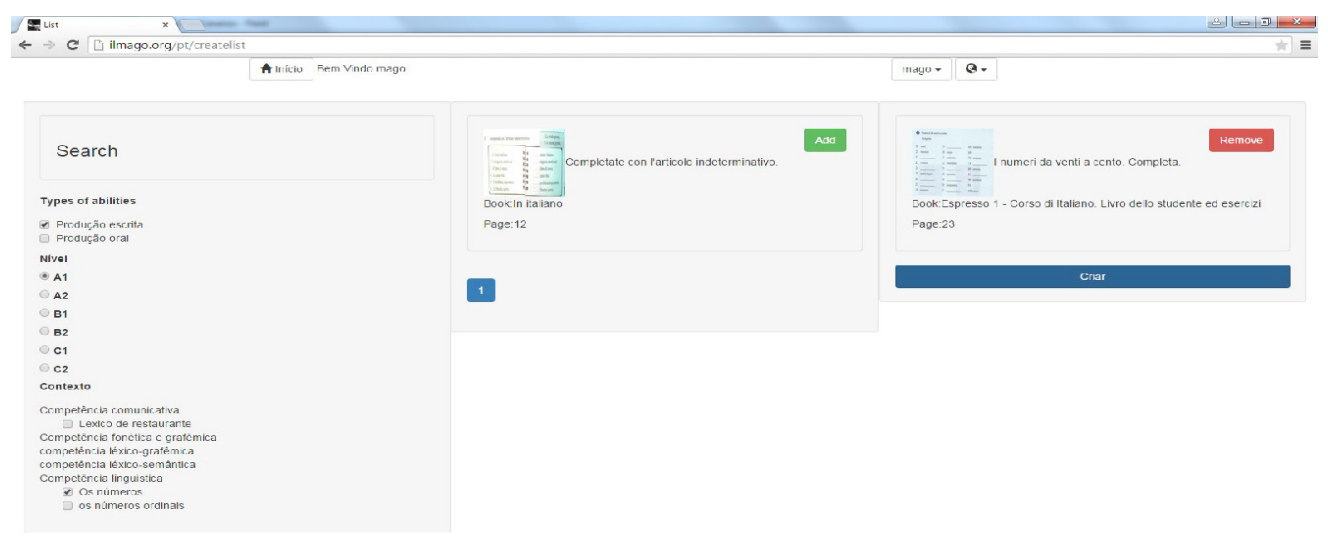


Caso o professor desista do exercício adicionado à lista, ele pode removê-lo clicando no botão "remove" na área de previsão da lista e o exercício será removido.

Para criar a lista, basta clicar em "criar". Aparecerá uma tela com o elenco de todas as listas já feitas conforme a Fig. 19. Elas são nomeadas de acordo com o nível e a data da sua criação, possuindo inclusive informações como o número de exercícios que possuem.

Figura 19. Elenco das listas já feitas.

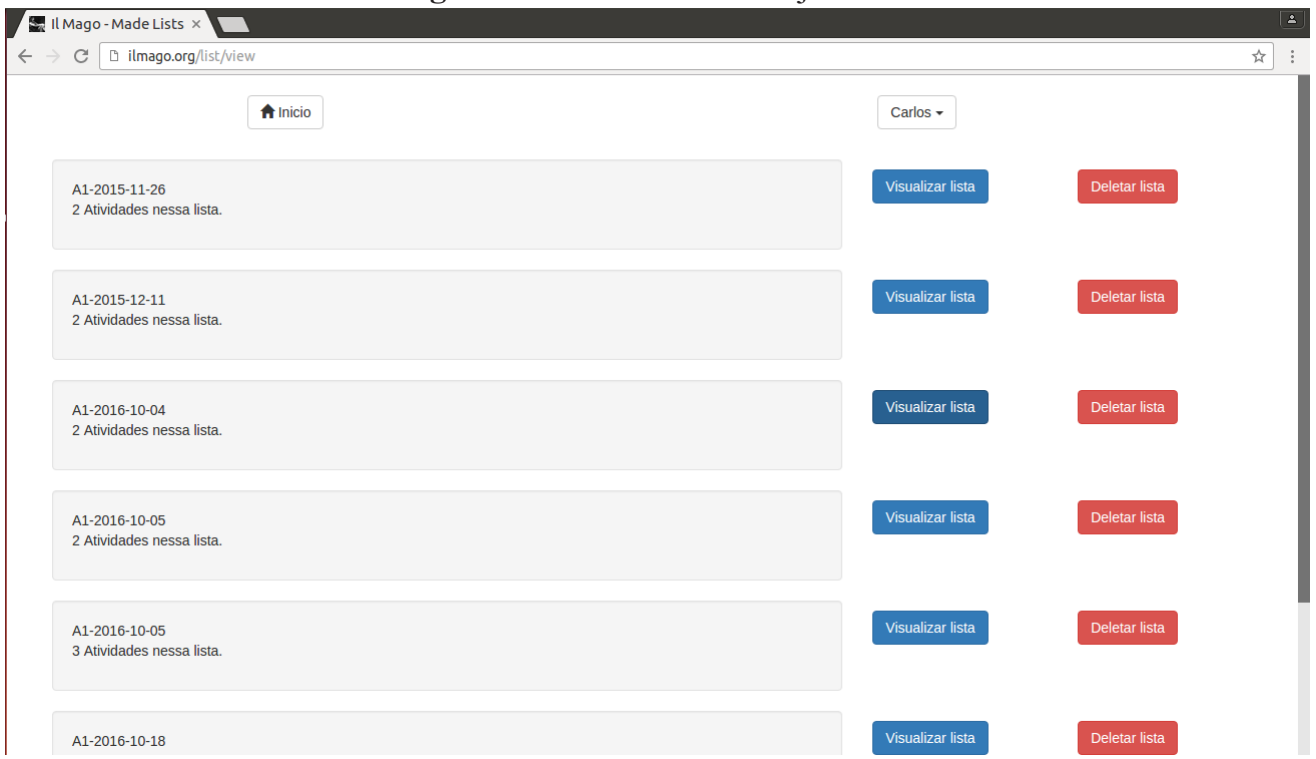

Para visualizar a lista feita, partindo da Fig. 19, basta clicar em "visualizar lista". Depois, para imprimir, utilizar a opção do navegador como no exemplo ilustrado na Fig. 20 a seguir: 
Figura 20. Visualizando e imprimindo a lista de exercícios feita.

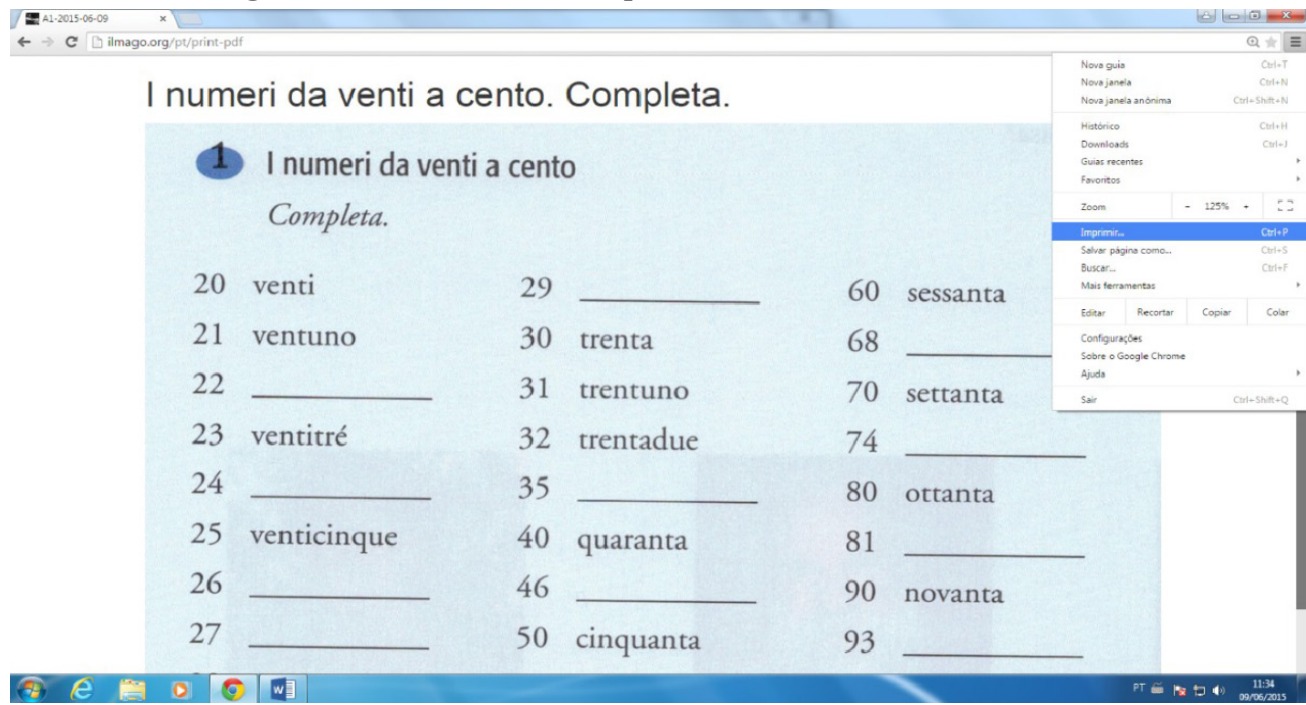

Após esse comando, o resultado será como apresentado na Fig. 21.

Figura 21 - Visualização da impressão da lista de exercícios

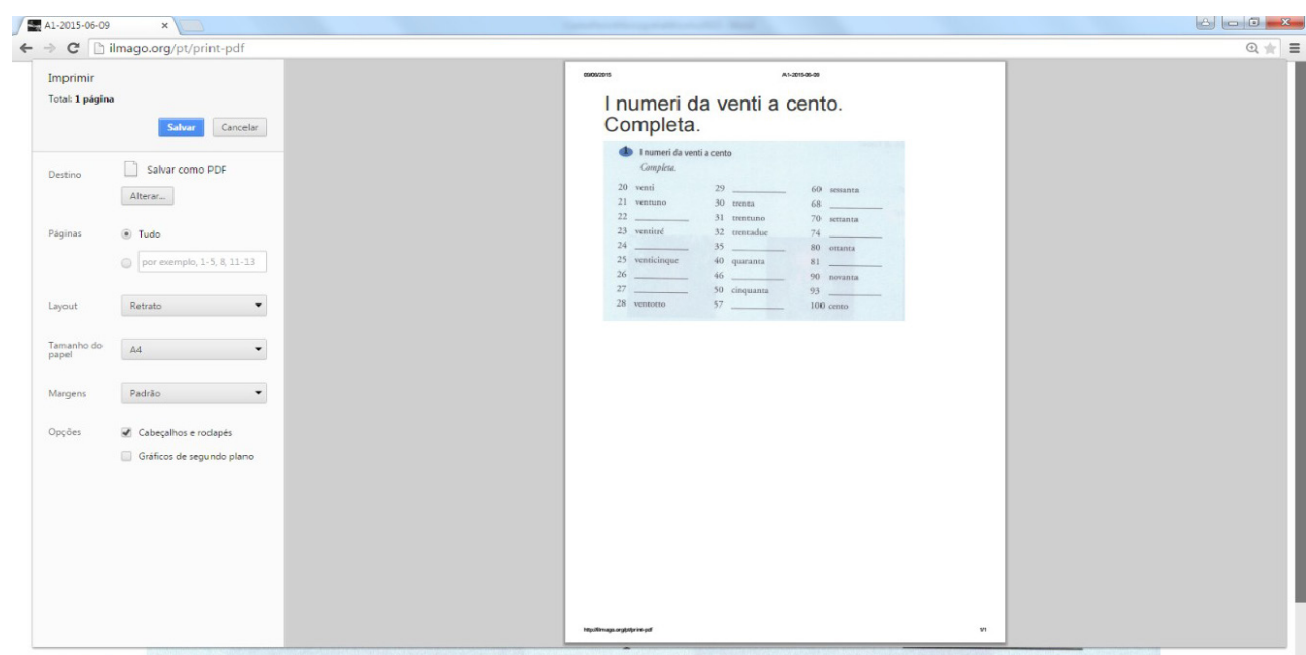




\section{Conclusão}

Pudemos dar uma visão mais ampla sobre o uso dos exercícios cadastrados nesse aplicativo e o resultado que ele permite realizar na forma de listas assim como sobre a maneira como os exercícios e as listas podem ser tratados com base no conceito de "objetos de aprendizagem". Um objeto de aprendizagem possui três características ${ }^{7}$ :

a) é um recurso digital modular, que utiliza como identificação metadados para identificação no apoio ao aprendizado;

b) incorpora qualquer recurso digital que pode ser reutilizado para apoiar o aprendizado;

c) apresenta a ideia principal de objetos de aprendizagem, que inclui a ideia de particionar o conteúdo educacional em pedaços (granulados) pequenos que possam ser usados de novo em vários ambientes de aprendizagem diferentes.

Uma metáfora para deixar mais clara a ideia dos objetos de aprendizagem é a do lego e a do átomo.

\begin{tabular}{|c|c|}
\hline LEGO & ÁTOMO \\
\hline $\begin{array}{l}\text { - Pode controlar ou limitar as pessoas no modo } \\
\text { de pensar em objetos de aprendizagem; } \\
\text { - Qualquer bloco de Lego é combinável com } \\
\text { qualquer outro bloco de Lego; } \\
\text { - O Lego pode ser montado da maneira que você } \\
\text { escolher; } \\
\text { - Os blocos de Lego são pura diversão e qualquer } \\
\text { criança é capaz de reuni-los }\end{array}$ & $\begin{array}{l}\text { - Apesar de pequeno, pode ser combinado e } \\
\text { recombinado com outros átomos para formar } \\
\text { coisas maiores; } \\
\text { - Nem todo átomo pode ser combinado com todo } \\
\text { outro átomo; } \\
\text { - Só podem ser combinados ou ajuntados átomos } \\
\text { em certas estruturas prescritas pela própria } \\
\text { estrutura interna dos mesmos. } \\
\text { - É necessário algum conhecimento para unificar } \\
\text { átomos. }\end{array}$ \\
\hline
\end{tabular}

A criação de objetos de aprendizagem deve vislumbrar a sua reutilização e não deve restringir-se apenas ao armazenamento de dados. Para isso, é necessário que seus autores utilizem, por exemplo: palavras-chave, autores das obras, conteúdo, e como poderão se relacionar com outros módulos. No aplicativo, as palavras-chave, autores de obras e conteúdo equivalem à funcionalidade de inserção e catalogação de um exercício no sistema. O relacionamento com outros módulos significa o modo como o professor compõe a lista, seguindo uma coerência equilibrada da tipologia e das competências que cada exercício tem como propósito, bem como

7 A definição foi inspirada na monografia de final de curso de SANTOS, S. H., intitulada E-Learning Object. Objetos de aprendizagem e apresentada em 2005 na UFMG. 
o que o professor está trabalhando em sala de aula. Uma boa lista de exercícios é aquela que não é muito extensa e que atinge as quatro habilidades de produção e compreensão oral e escrita.

No caso do ensino de línguas, existem situações de classificação que se sobrepõem. Por exemplo, na competência léxico-semântica, ao trabalhar o campo semântico de cozinha, em algum momento lidamos com receitas e, nesse caso, na competência linguística, devem ser inseridos os verbos no modo imperativo. Isto é, quando selecionarmos "léxico de cozinha", virão, entre outros, exercícios para o imperativo; assim como, quando selecionarmos "imperativo", virão, entre outros, exercícios contendo receitas da cozinha italiana, por exemplo. Da mesma maneira, essa superposição ocorre para o condicional e situações de uso como dúvidas ou conselhos. Ou ainda, exercícios sobre o passato remoto vêm junto de biografias e outros textos referentes a tempos "mais antigos" ou "psicologicamente distantes".

Ensinar os critérios para mapear/agrupar exercícios aos professores que usarão o aplicativo é essencial, assim como mostrar que há casos de multiplicidade de usos (pode-se trabalhar, por exemplo, léxico e cultura de imigração, mas, ao mesmo tempo, também estruturas da gramática). $\mathrm{O}$ aplicativo foi feito pensando nessa sobreposição, pois pode-se selecionar um ou outro e o exercício aparecerá para ser incluído na lista, e o trabalho de mapeamento do índice é feito para preparar o aplicativo a receber os exercícios, caso contrário pode não haver item de classificação para o livro que será inserido no sistema. Como foi observado por usuários do aplicativo ${ }^{8}$, outra função importante é a possibilidade de classificar vários tipos de gêneros textuais, por exemplo: romances, bilhetes, horóscopo, receita culinária, lista de compras, e-mail etc.

O primeiro resultado do trabalho aqui apresentado é um aplicativo para, por exemplo, a autoaprendizagem da língua italiana. O segundo resultado é aquele oriundo da comparação dos índices dos livros com os do QECR, que são as informações utilizadas para a classificação e a seleção dos exercícios. Outro resultado - a nosso ver, o principal - é o aplicativo propriamente dito disponível em www.ilmago.com.br, realizado utilizando parcialmente a metodologia PRAXIS, em especial nas partes de descrição dos casos de uso, prototipação de interfaces e manual de uso.

O contexto digital de hoje permitiu a transferência das tecnologias do laboratório linguístico de exercitação das quatro habilidades para qualquer computador ligado à rede. Futuros refinamentos no aplicativo serão feitos, como a inclusão de módulos para gestão de usuários e módulos pensados para a autoaprendizagem do aluno. Enfrentar esses refinamentos significa investigar os aplicativos de suporte didático existentes, compará-los e avaliá-los.

Esse instrumento facilita a realização dos hábitos de organização/classificação/planejamento de aulas e listas de exercícios de modo prático. Selecionar, classificar, resolver exercícios para o 
ensino e a aprendizagem de língua italiana é um trabalho contínuo para a formação do professor e o aplicativo que propomos é, portanto, uma ferramenta de suporte para esse ofício.

\section{Referências}

CHIUCHIÚ, A.; CHIUCHIÚ, Gaia. Italiano IN. Vol.1. Perugia: Guerra Edizioni, 2010.

CONFORTI, C., Nuovo Linea Diretta. Vol.1a. Perugia: Guerra Edizioni, 2005.

CONSELHO DA EUROPA, Quadro Europeu Comum de Referência para as línguas (QECR). Aprendizagem, ensino, avaliação. Tradução do inglês de Maria Joana Pimentel do Rosário e Nuno Verdial Soares. Porto/Lisboa: Asa Edições, 2001.

DE MAURO, T., Lessico di frequenza dell'italiano parlato. Milano: Etas Libri, 1993.

FILHO, W. de P. Paula., Engenharia de Software: Fundamentos, Métodos e Padrões. Rio de Janeiro: LTC, 2003.

MAGNELLI, S. e MARIN, T. Nuovo Progetto Italiano. Vol.1a. Roma: Edilingua Edizioni, 2013.

PICHIASSI, M., Apprendere l'italiano L2 nell'era digitale. Le nuove tecnologie nell'insegnamento e nell'apprendimento dell'italiano per stranieri. Perugia: Guerra, 2007.

REVISTA DO ARQUIVO PÚBLICO MINEIRO, Ano XLIII, nº 1, Jan.-Junho 2007, p. 160. Disponível em: http://www.siaapm.cultura.mg.gov.br/modules/rapm/search.php. Acesso: 05/05/2016.

SANTOS, R., A aquisição da linguagem. In: FIORIN, J. L. (org.), Introdução à Linguística - Objetos Teóricos, São Paulo: Contexto, 2002, p. 211-226.

SCIARONE, G., Vocabolario fondamentale della lingua italiana. Perugia: Guerra Edizioi, 1995.

SPINELLI, B.; PARIZZI, F., Profilo della lingua Italiana. Firenze: La Nuova Italia, 2010.

ZAMBALDE, A. L.; PÁDUA, C. I. P. S., O documento científico em Ciência da Computação: suas partes e sua redação: estudo e análise em uma Instituição Federal de Ensino Superior. 2006. Disponível em: http://algol.dcc.ufla.br/ zambalde/aulas/02_COM211_ArtigoExemplo.doc. Acesso: 05/05/2015.

ZIGLIO, L.; RIZZO, G., Espresso. Vol.1. Firenze: Alma Edizioni, 2003.

ZUANELLI, E., Comunicazione Digitale. Un approccio semiologico-linguistico. Roma: Colombo, 2009.

Recebido em 10/05/2016

Aprovado em 25/10/2016 